\title{
A STUDY OF CORONARY DOMINANCE IN POPULATION OF NORTH
} KARNATAKA

\author{
Pratik Khona ${ }^{1}$, Ashwini C $* 2$. \\ ${ }^{1}$ Assistant professor, Dept of Anatomy, Gadag Institute of Medical Sciences, Gadag, Karnataka, \\ India. \\ *2 Assistant professor, Dept of Anatomy, Gadag Institute of Medical Sciences, Gadag, Karnataka, \\ India.
}

\section{ABSTRACT}

Introduction: With the increase in the trend of modern sedentary lifestyle, the coronary heart diseases have also increased. The need to understand coronary artery anatomy in detail has become ever so important because of wide variations in the anatomy and various anomalies noted in different populations. Knowledge of coronary dominance is important to understand the severity of coronary artery diseases and plan the treatment of cardiovascular diseases. It determines the amount of myocardium that is perfused by the left or right coronary circulation.

Materials and Methods: 100 adult formalin fixed heart specimens were collected from routine under graduate and post graduate dissection at Belgaum Institute of Medical Sciences, Belagavi irrespective of sex and age. The origin of posterior interventricular artery was examined and dissected. Results were noted and compared with previous studies.

Results: Out of 100 specimens studied in 83 (83\%) specimens the posterior interventricular artery was arising from right coronary artery and in other 17 (17\%) specimens it arose from Left circumflex artery. In none of the specimens studied the posterior interventricular artery was arising from both the coronary arteries.

Conclusion: The knowledge of normal anatomy and variations of coronary dominance will help interventional cardiologist, cardio-thoracic surgeons and radiologist of North Karnataka region in proper management of patients.

KEY WORDS: Coronary Dominance, coronary artery disease, Left coronary dominance, Right coronary dominance, co-dominance.

Address for Correspondence: Dr. Ashwini C, Assistant Professor, Dept of Anatomy, Gadag Institute of Medical Sciences, Gadag, Karnataka, India. Mob: 7812929192

E-Mail:meashumbbs@gmail.com

Access this Article online

Quick Response code

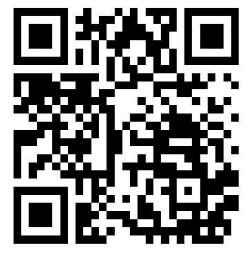

DOI: $10.16965 /$ ijar.2018.104

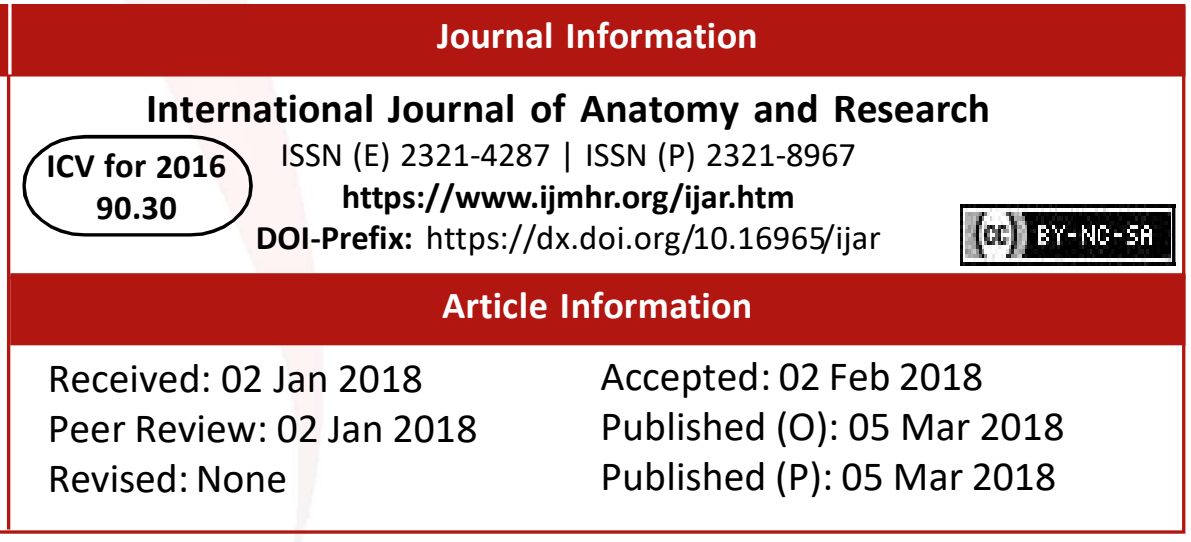

conditions like hypertension and diabetes [1]. Normally the heart is supplied by two coronary arteries: right coronary artery (RCA) and left coronary artery (LCA). There is a wide variation with regard to origin, course, termination and branching pattern of coronary arteries as reported in literature. The term 'dominant' is used 
to refer to the coronary artery giving off the posterior interventricular artery (PIVA) which supplies the posterior part of the ventricular septum and often part of the posterolateral wall of the left ventricle [2]. In 'right dominance', the PIVA is derived from the right coronary; in 'left dominance' it is derived from the left. In the so called 'balanced' pattern, branches of both arteries run in or near the groove [2]. The RCA is dominant in $67 \%$ of people. In $15 \%$ of hearts 'left dominance' is present in that circumflex artery $[\mathrm{LCX}]$ which is a branch of LCA gives the PIVA. In these cases the RCA is small and does not supply the left ventricle. In approximately $18 \%$ of people both RCA and LCx reach the crux and give rise to branches which course in or near the posterior inter ventricular groove [3].

Though right dominance is more prevalent, Coronary Artery Disease (CAD) is more common with those having left dominance circulation [4]. Left dominance is believed to be associated with worse prognoses for patients with acute coronary syndrome (ACS) and stable coronary artery disease $[5,6]$. Knowledge of coronary artery dominance and variations in blood supply of myocardium is important in interpretation of findings and planning the treatment of cardiovascular diseases, hence the present study was conducted to help interventional cardiologists, radiologists and cardiothoracic surgeons understand better.

\section{MATERIALS AND METHODS}

A total of 100 formalin fixed adult heart specimens were collected from routine under graduate and post graduate dissection at Belgaum Institute of Medical Sciences, Belagavi irrespective of age, sex, educational or socioeconomic status. Hearts with any congenital anamolies, damage due to trauma or external deformities were excluded. Visceral pericardium was stripped and subepicardial fat was removed to study the coronary artery and its branching pattern. The branches were dissected manually and carefully till their termination.The coronary artery which gives the PIV artery and determines the coronary preponderance was examined in detail. Photographs were taken wherever necessary. The data was collected, analyzed and compared with previous studies.

\section{RESULTS}

The artery which was running in the Posterior interventricular sulcus (PIVS) was the PIVA. Whenever the RCA or LCx reached the crux it was seen that PIVA arose from the artery as $L$ shaped terminal branch. Whenever the RCA or LCx crossed the crux then PIVA aroused as a side branch. The PIVA was seen supplying myocardium for varying distance and was in most of the cases ending by anastomosing with anterior interventricular artery. Hence PIVA had varying course.

The PIVA was seen to arise from the RCA in 83 $(83 \%)$ of specimens (Photo No 1 ) while it was seen arising from the LCx artery in $17(17 \%)$ of specimens (Photo No 2) as shown in Table no 1. In none of the specimens studied there were PIVA from both the arteries. The PIVA terminated $1 / 2$ way down PIVS in 48 (48 \%) specimens out of 100 specimens studied. It terminated $3 / 4^{\text {th }}$ way down PIVS in 39 (39\%) specimens, at apex in 12 (12\%) specimens (Photo no 1 ) and $1 / 4^{\text {th }}$ way down the PIVS in 1 ( $1 \%$ ) specimen (Photo no 2 ) as seen in Table No 2.

As the artery giving the PIVA branch decides the dominance, hence, in the present study the right dominance, left dominance and co dominance were found to in $83 \%, 17 \%$, and none of the specimens respectively.

Table 1: Showing the pattern of origin of PIVA in present study.

\begin{tabular}{|c|c|c|}
\hline $\begin{array}{c}\text { PIVA originating } \\
\text { from }\end{array}$ & $\begin{array}{c}\text { No. of } \\
\text { Specimens }\end{array}$ & Percentage \\
\hline LCA & 17 & $17 \%$ \\
\hline RCA & 83 & $83 \%$ \\
\hline Both & 0 & 0 \\
\hline
\end{tabular}

Table 2: Showing the distribution of level of termination of the PIVA in present study.

\begin{tabular}{|c|c|c|c|}
\hline \multicolumn{2}{|c|}{ Level of Termination of PIVA } & $\begin{array}{c}\text { No. of } \\
\text { Specimen }\end{array}$ & Percentage \\
\hline I & $1 / 4^{\text {th }}$ way down PIVS & 1 & $1 \%$ \\
\hline ii & $1 / 2$ way down PIVS & 48 & $48 \%$ \\
\hline iii & $3 / 4^{\text {th }}$ way down PIVS & 39 & $39 \%$ \\
\hline iv & At the Apex & 12 & $12 \%$ \\
\hline
\end{tabular}

Table 3: Showing the comparison of pattern of origin of PIVA with previous workers.

\begin{tabular}{|c|c|c|c|c|}
\hline $\begin{array}{c}\text { PIVA originating } \\
\text { from }\end{array}$ & $\begin{array}{c}\text { Shilpa Bhimalli et al. } \\
(\mathrm{n}=60)\end{array}$ & $\begin{array}{c}\text { Hirak Das et al. } \\
(\mathrm{n}=70)\end{array}$ & $\begin{array}{c}\text { Kalpana R } \\
(\mathrm{n}=100)\end{array}$ & $\begin{array}{c}\text { Present study } \\
(\mathrm{n}=100)\end{array}$ \\
\hline LCA & $23.33 \%$ & $18.50 \%$ & $11 \%$ & $17 \%$ \\
\hline RCA & $60 \%$ & $70 \%$ & $89 \%$ & $83 \%$ \\
\hline Both & $16.66 \%$ & $11.50 \%$ & 0 & 0 \\
\hline
\end{tabular}


Fig. 1: Showing the PIVA originating for RCA and ending before apex.

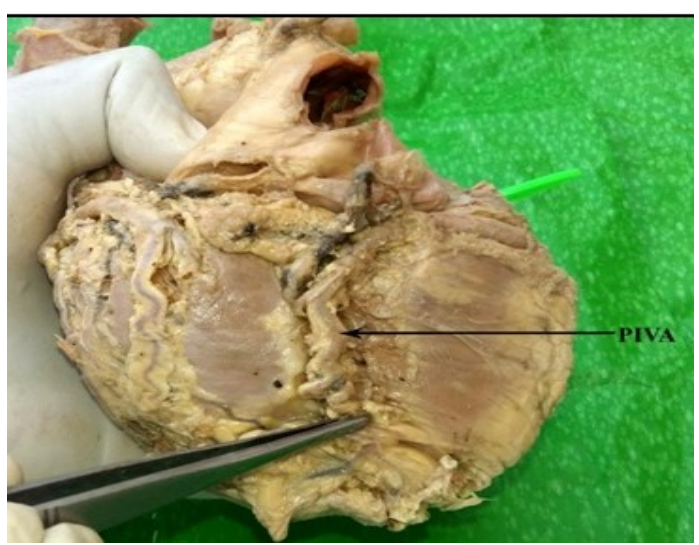

Fig. 2: Showing the PIVA originating from LCx and ending $1 / 4^{\text {th }}$ way down PIVS.

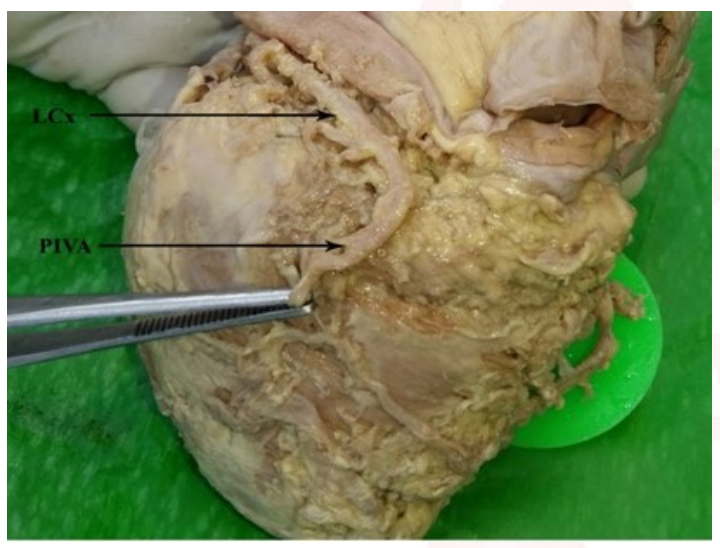

\section{DISCUSSION}

The dominance of coronary artery is determined by the posterior interventricular artery (PIVA). It is termed as right dominance if PIVA is a branch of RCA, left dominance if PIVA is a branch of LCA and co-dominant if PIVA is given by both by RCA and LCA. Dominance pattern of heart has important clinical significance. Left dominance was found to have significantly higher mortality than right dominance and mixed type [5].

Dominance also showed a role in left anterior descending artery stenosis. It was observed that in left dominance, the LAD usually wraps around the apex of the heart, supplying the major portion of the myocardium. In contrast, in right dominance, it was the posterior interventricular branch of the RCA that supplied the most of the myocardium. As such, lesions in LAD would have more profound clinical importance in a left dominant heart than in a right dominant one [7].

Dominance also plays an important part in inferior infarcts of the heart. Inferior infarcts though less frequent than anterior infarcts are more important as they can cause varying degrees of atrioventricular block in approximately $30 \%$ of cases. The dominant RCA usually supplies AV node. Therefore inferior infarcts caused by occlusion of RCA will have higher risk of AV block [8].

The PIVA originated from LCA in $11 \%$ specimens studied by Kalpana [9], $23.33 \%$ specimens studied by Shilpa B et al. [10]. and in $18.5 \%$ specimens studied by Hirak Das et al. [11]. In the present study it originated from LCA in $17 \%$ specimen which was similar to study by Hirak Das et al. [11]. In $16.66 \%$ and $11.5 \%$ specimens studied by Shilpa B et al. [10] and Hirak Das et al. [11] the PIVA originated from both LCA and RCA, but no such specimens were found in present study as seen in Table No 3.

On comparison with previous studies the PIVA terminated $3 / 4^{\text {th }}$ way down the PIVS in $39 \%$ specimens which was similar to the study by James [12] (40\%). The PIVA terminated $1 / 2$ way down PIVS in $48 \%$ specimens in present study, it did the same in $53 \%$ specimens studied by Kalpana [9]. The PIVA terminated at the apex in $12 \%$ specimens which was similar to the study done by Shilpa B et al. [10] (10\%). The PIVA terminated $1 / 4^{\text {th }}$ way down the PIVS in $1 \%$ specimens in present study which was similar to the study by James [12]. The findings where similar to that of the study done by Shilpa B et al. [10] which suggest that regional variations may be the reason for different results.

A compensatory phenomenon has been observed in the irrigation of the heart's posteriorinferior segments because of a short posterior interventricular branch due to the distal segment of the LAD overcoming the apex and irrigating neighbouring territory on the diaphragmatic side. Such anatomical expression must be considered when evaluating a myocardium heart attack located in the inferior segment of the posterior wall of the heart, since arterial obstruction could compromise the distal portion of the LAD instead of the posterior interventricular branch, as is usually assumed [13]. Although right dominance circulation is more common in general population, both the coronary diseases and coronary artery variations are more common in individuals with left dominance circulation [14]. Several studies have confirmed the 
relevance of left coronary artery dominance in the outcome and prognosis of obstructive CAD. Therefore, it is conceivable that the type of coronary artery dominance also has an effect on the occurrence and outcome of non obstructive CAD [15]. In patients with acute coronary syndrome, left dominance is a significant and independent predictor of increased long-term mortality [5].

In patients with ST-segment elevation myocardial infarction (STEMI), a left-dominant coronary artery system is linked with higher risk of 30day mortality and early reinfarction compared with right dominance [16].

Though many studies by foreign authors and Indian authors show balanced co-dominance vary from $0-34 \%$ in present study we did not find any case with the same.

\section{CONCLUSION}

We can conclude that most common is the right coronary dominance compared to left and balanced dominance as seen in this study and also in the studies done by previous workers. This knowledge of normal anatomy and variations of coronary dominance will help interventional cardiologist, cardio-thoracic surgeons and radiologist of North Karnataka region to plan and provide proper management to patients.

\section{Conflicts of Interests: None}

\section{REFERENCES}

[1]. Priyadharshini. S, Sivakumar. M. A Study of Coronary Arterial Dominance Pattern. Int J Anat Res 2016; 4(3):2817-2821.

[2]. Standring S (Editor in chief). Gray's Anatomy. The Anatomical Basis of Clinical Practice. 40th ed.Spain: Churchill Livingstone.Elsevier. 2008; 978- 81.

[3]. Moore KL, Dalley AF, Agur AMR. Clinically Oriented Anatomy.6th ed. Baltimore: Lippincott Williams \& Wilkins, Wolters Kluwer. 2010; 144 - 47.

[4]. Mian FA, Malik SN, Ismail M, Khan IS, Rehman M et al. Coronary artery dominance: What pattern exists in Pakistani population? Ann. Pak. Inst. Med. Sci. 2011;7(1):3-5.
[5]. Goldberg A, Southern DA, Galbraith PD, Traboulsi M, Knudtson ML, et al. Coronary dominance and prognosis of patients with acute coronary syndrome. Am Heart J 2007; 154: 1116-22.

[6]. Veltman CE, de Graaf FR, Schuijf JD, van Werkhoven JM, Jukema JW, et al. Prognostic value of coronary vessel dominance in relation to significant coronary artery disease determined with non-invasive computed tomography coronary angiography. Eur Heart J 2012; 33: 1367-77.

[7]. Ilia R, Rosenshtein G, Marc WJ, Cafri C, Abu-Ful A, Gueron $M$. Left anterior descending artery length in left and right coronary artery dominance. Coronary Artery Disease 2001; 12: 77-78.

[8]. Amin K, Javed M, Mehmood A, Zakria M. Acute Inferior Wall Myocardial Infarction: Frequency of AV Blocks. The Professional. 2004 Jan, Feb, Mar; 11(1): 31-37.

[9]. Kalpana, R. A study on the principal branches of coronary arteries in humans. Journal of Anatomical Society of India 2003; 52 (2): 137-40.

[10]. Bhimalli S, Dixit D, Mahantesh S, Shirol VS. A Study of Variations in Coronary Arterial System in Cadaveric Human Heart, World Journal of Science and Technology 2011; 1(5):30-35.

[11]. Das H, Das G, Das DC and Talukdar K. A study of coronary dominance in the population of Assam. Journal of Anatomical Society of India 2010; 59(2):187-91.

[12]. James T.N: Anatomy of the coronary arteries. $1^{\text {st }}$ Edn; Hoeber Med Div, Harper \& Row: New York. (1961).

[13]. L.E. Ballesteros, L.M. Ramirez. Morphological expression of the left coronary artery: a direct anatomical study. Folia Morphologica 2008; 67 (2):135142.

[14]. Eren, Bayram E, Fil F, Koplay M, Sirvanci M, Duran C et al. An investigation of association between coronary artery dominance and coronary artery variations with coronary arterial disease by multidetection CT coronary angiography. Journal of computer assisted tomography Dec 2008: 32(6): 929-33.

[15]. Makarovic Z, Sandra Makarovic, Ines Bilic-Curcic. Sex-dependent association between coronary vessel dominance and cardiac syndrome $X$ : a casecontrol study: BMC Cardiovasc Disord. Oct 2014:m14:142.

[16]. Veltman CE, Van der Hoeven BL, Hoogslag GE. Influence of coronary vessel dominance on shortand long-term outcome in patients after ST-segment elevation myocardial infarction. Eur Heart J. 2014; doi:10.1093/eurheartj/ehu236.

How to cite this article:

Pratik Khona, Ashwini C. A STUDY OF CORONARY DOMINANCE IN POPULATION OF NORTH KARNATAKA. Int J Anat Res 2018;6(1.3):5030-5033. DOI: 10.16965/ijar.2018.104 